\title{
Treatment of Repeat Breeding in Dairy Cows with Lugol's Iodine
}

\author{
Faisal Omer Ahmed ${ }^{1}$ and Adil Salim Elsheikh ${ }^{1,2}$ \\ ${ }^{I}$ Department of Reproduction and obstetrics, Faculty of Veterinary Medicine, University of Khartoum, Shambat, \\ P.O. Box 32, Sudan \\ ${ }^{2}$ Department of Applied Medical Sciences, Community college, Najran University, Saudi Arabia
}

\begin{abstract}
This study was carried out to see whether the uteri of dairy cows suffering from repeat breeder syndrome are infected with bacteria or not. Furthermore, the efficacy of intra-uterine infusion of diluted Lugol's iodine to treat this syndrome was tested by studying two reproductive traits, the rate of service per conception and the length of the days open (DO). Sixty cross-bred dairy cows that were diagnosed as repeat breeders were used. A transcervical guarded sterile disposable swabs were collected from the endometria of the cows. The swabs were transferred to sterile test tubes and were cultured aerobically onto a pre-equilibrated MacConkey blood agar within 2 hour of collection. The bacteria were identified based on the characteristic of the colonies, Gram-staining and their morphology. The bacterial growth was scored semi-quantitatively. The bacteriological examination revealed that the uteri of all the repeat breeder cows are infected. The cows were then distributed randomly to three groups, group A $(n=20 \mathrm{cows})$ was intra-uterine infused with $1 \%$ Lugol's iodine 6 hours pre-servicing, group $B(n=20$ cows) was infused with the same solution 6 hours post-servicing and a control group ( $n=20$ cows) was serviced without treatment. Intra-uterine infusion of diluted Lugol's iodine 6 hours pre or post servicing significantly $(P<0.001)$ reduced the rate of service per conception and the length of the DO compared to the control. It is concluded that, the repeat breeding syndrome in dairy cows, is most likely caused by sub-clinical endometritis and can be treated successfully with intra-uterine infusion of $1 \%$ Lugol's iodine.
\end{abstract}

Keywords: cow, Lugol's iodine, repeat breeding syndrome.

\section{Introduction}

A repeat breeder cow is a cow that looks apparently healthy and has regular oestrous cycle $[1 ; 2]$, however, it does not conceive when bred three times continuously, either with a bull of well-known fertility or inseminated artificially with excellent semen quality [3]. Repeat breeding is one of the major infertility problems of herds [4]. The incidence of repeat breeding in dairy cows, worldwide, ranges from 3 to $10 \%,[4 ; 5]$. The potential causes of the repeat breeding mainly include subclinical endometritis [6;7], nutritional deficiency, specially trace minerals and vitamin A [8;9;10], age of the dam [4], improper heat detection [11], and endocrine dysfunction [12;13]. In the Sudan, there is a very high incidence (35\%) of repeat breeding in cross-bred dairy cows which could be mainly as a sequel of postpartum (PP) subclinical endometritis, nutritional insufficiency, poor management, natural servicing with sub-clinically infected bulls or heat stress [10]. The repeat breeding causes great economic losses for dairy farmers [3;4]. The costs of herds management and rearing are increased by increment of expenses of unsuccessful frequent artificial insemination (AI), extended length of the days open (DO) as well as culling and replacement of those cows that can't conceive. Additionally, treatment of the repeat breeding with antibiotics and hormones increases the expenses beside its public health hazard and its inconsistent results. Recently there has been some interest in finding new effective protocols for treatment uterine bacterial infection in dairy cows such as intra-uterine infusion of diluted iodine compounds [10;14] or injection of insulin [15]. The objectives of the present study were to examine whether repeat breeding syndrome among Sudan dairy cows is associated with uterine bacterial infection or not. Furthermore, the intra-uterine infusion of diluted Lugol's iodine was tested as a remedy for this syndrome.

\section{Materials And Methods}

1. Study area: This study was carried out at Khartoum University Dairy Farm about four Km north to the Faculty of Veterinary Medicine, Shambat, North Khartoum, Sudan.

2. Animals: The study was conducted on 60 cross-bred (Friesian $\times$ Kenana) dairy cow 4 to 7 years old. Their body condition score (BCS) varied from 3.00 to 3.50 , according to the five-scale point system outlined elsewhere [16]. In this scale emaciated cows were scored 1.00; thin cows 2.00 , average cows 3.00 , fat cows 4.00 and obese cows were scored 5.00. The cows were diagnosed as repeat breeders depending on their failure to conceive after frequent servicing with bulls of known fertility and/or insemination with excellent semen. 
3. Uterine swabs collection and bacteriology: A transcervical guarded sterile disposable swabs were collected from the endometria of the cows. The swabs were transferred to sterile test tube and cultured aerobically onto a pre-equilibrated MacConkey blood agar within 2 hour of collection. Identification of the bacteria was based on the characteristic of colony, Gram-staining and morphology [17]. Bacterial growth on the cultured plates was scored semi -quantitatively depending on the number of bacterial colonies detected on the plate: 0 no growth; $1<10$ colonies 2; 10 to 100 colonies 3; 100 to 500 colonies and $4>500$ colonies [18].

4. Heat detection and servicing: A well-trained herd man visually checked the cows for oestrus signs thrice a day: early in the morning at 7:00 am, in the mid-day at 12:00 and at 7:00 pm for at least 30 minutes [19]. The cow that became restless, licked the perineum of other cows, jumped on other cows, allowed other cows or bull to mount her, bellowed frequently and a transparent clear vaginal mucus discharge hanged from its vulva, is recorded in oestrus. The cow is considered in a full response when it stood to be mounted by the bull and mating was completed $[19 ; 20]$. Cows in oestrus were serviced with a bull of known fertility.

5. Number of services per conception, Days open (DO) and Pregnancy diagnosis: Number of services per conception was calculated according to Elsheikh and Ahmed [21]. It is the number of services given to the animals that display oestrus signs and resulted in a confirmed pregnancy. Days open were counted by calculating the intervals in days from calving to the subsequent effective service date of those cows that conceived $[19 ; 20]$. Pregnancy diagnosis was carried out for none retain cows by rectal palpation at 60 days after the last service [21].

6. Intra-uterine infusion of $1 \%$ Lugol's iodine: A volume of $150 \mathrm{ml}$ of $1 \%$ Lugol's iodine ( $10 \%$ potassium iodide, $5 \%$ iodine and $85 \%$ distilled water) was infused into the uteri of the repeat breeder dairy cows at 6 hours pre-servicing or post-servicing [22]. The apparatus used for uterine infusion consisted of a 2 liter stainless steel jug with a projected nozzle at the bottom. A rubber tube of $100 \mathrm{~cm}$ long connected with 30 $\mathrm{cm}$ catheter was fitted to the nozzle of the apparatus [23].

7. Experimental procedure: This experiment was conducted to study the efficacy and potency of diluted Lugol's iodine as an innovation therapeutic protocol for repeat breeder syndrome in dairy cows. Two reproductive traits were studied. These traits were DO and the rate of service per conception. The sixty cross-bred repeat breeder dairy cows after been bacteriologically examined, and proofed sub-clinically infected, they were then grouped randomly into 3 groups A, B and C ( $\mathrm{n}=20$ cows each). Group A and B were infused with $150 \mathrm{ml}$ diluted Lugol's iodine 6 hours pre and post servicing, respectively [24]. Group C $(\mathrm{n}=20$ cows) were used as untreated control. The DO and the rates of service per conception were assessed as described above. The cows that do not conceive after the first treatment were re-serviced in the next oestrus with the same treatment protocol.

8. Statistical analysis: Data generated were subjected to analysis of variance (ANOVA) followed by Fisher's exact test in a one factorial design using Stat View Analytical Computer Package version 4.01. Significant differences at $\mathrm{P}<0.001$ were considered.

\section{RESULTS}

1. Bacteriological findings: The uteri of all the repeat breeder cows were found infected. The common pathogenic bacteria isolated from the endometria of the repeat breeders in this study were Strep. spp. $35.00 \%$, Staph. spp. $28.30 \%$, E. coli $25.00 \%$, Coryn. spp. $8.30 \%$, Pasteurella spp. $3.40 \%$.

2. Rate of service per conception: Figure (1) showed that, the rate of service per conception in repeat breeder dairy cows was significantly $(\mathrm{P}<0.001)$ reduced by infusion of diluted Lugol's iodine. cows The mean rate of service preconception for pre servicing infused, post servicing infused cows and the control was $1.00 \pm$ $0.00,1.40 \pm 0.10$ and $4.80 \pm 0.20$, respectively. 


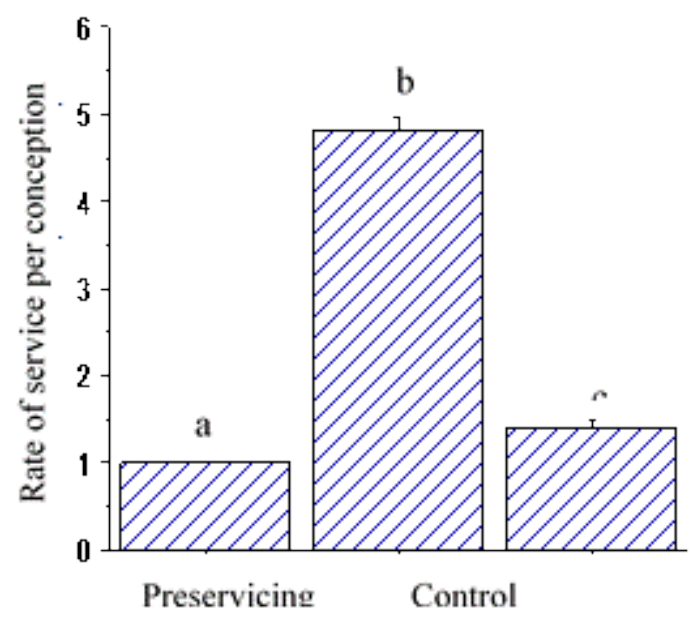

Fig. 1 The effects of intra-uterine ifusion of Lugol's iodine pre or post servicing on the rate of service per coception in repeat breeder dairy cows $\left({ }^{\mathrm{a}, \mathrm{b}, \mathrm{c}} \mathrm{P}<0.001\right)$.

3. Days open (DO): As shown in figure (2) the length of the DO of the repeat breeder dairy cows was significantly $(\mathrm{P}<0.001)$ reduced by infusion of Lugol's iodine pre or post servicing compared to the control. The mean length of the DO for the pre-serviced infused repeat breeder was $133.20 \pm 4.70$ days, the post-service infused cows was $145.05 \pm 5.28$ days and the control was $244.75 \pm 9.08$ days.

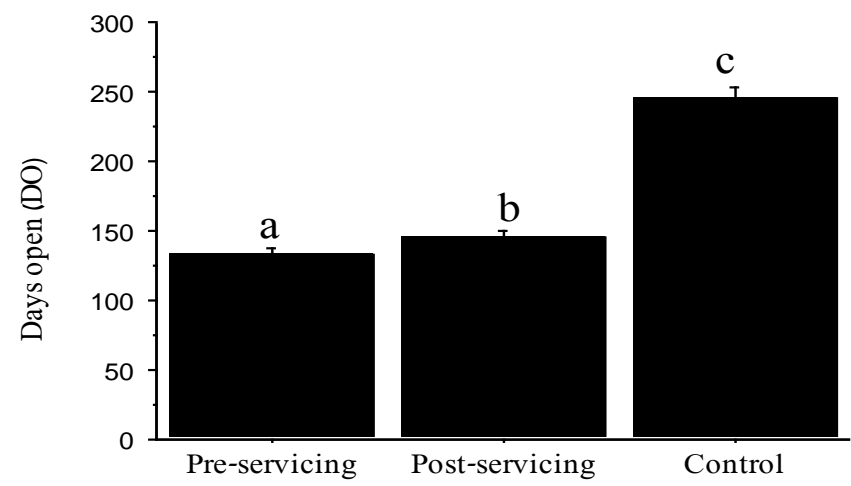

Fig.2 The effects of intra-uterine infusion of diluted Lugol`s iodine pre or post servicing on the length of the DO in repeat breeder dairy cows $\left({ }^{\mathrm{a}, \mathrm{b}, \mathrm{c}} \mathrm{P}<0.001\right)$.

\section{Discussion}

The present study clearly indicated that the repeat breeder syndrome among the Sudan cross-bred dairy cows is mainly due to subclinical endometritis. Furthermore, this problem could be solved by intra-uterine infusion of diluted Lugol's solution. Subclinical endometritis is mainly due to contamination of the genital tract of the cows via the descending bacterial infection [10] or contamination of the genital tract during intervention and maneuvering at the time of parturition $[7 ; 14)$. The bacteria and its products induces uterine inflammation and reduce pituitary FSH, suppress LH release. Consequently ovarian follicular growth and function is perturbed and the ovulation is delayed in the dairy cows leading to failure of fertilization [25]. If fertilization happens, the infection will perturb the embryo survival and implantation [26]. Also the subclinical endometritis may alters the $\mathrm{pH}$ of the genital tract of the infected cows leading to failure of conception [24]. Thus the repeat breeder cow syndrome develops. All the repeat breeder cows used in the current study were found infected and their repeat breeding is judged as subclinical endometritis. This finding is in agreement with that of Grohan and Saoloemi[27] who reported that subclinical endometritis leads to silent heat, failure of inseminations and repeat breeding in dairy cows. The repeat breeding could also be due to trace elements deficiencies particularly iodine deficiency. Iodine is essential for initiation of follicular wave dynamic, ovarian activities, release of best quality mature oocytes and improvement of rate of service per conception in dairy cows [28]. The infusion of diluted 
Lugol's iodine into the uteri of the repeat breeder dairy cows pre-servicing improved the conception rate and reduced the length of the DO. This improvement could be due to the potent bactericidal effects of the solution, adjustment of the reproductive tract $\mathrm{pH}$ before servicing, the slight hyperemia of the endometrium which enhanced uterine blood circulation and increased the defense mechanisms of the reproductive system that become reasonably efficient [28]. The infusion of diluted Lugol's iodine into the uteri of the repeat breeder dairy cows post-servicing had less effect on the rate of service per conception and the DO. This difference is definitely due to sub-clinical endometritis which disturbs the uterine $\mathrm{pH}$ and decreases the lively hood of the sperms. This result is also consistent with that of Koujan, et al[29] who reported that infusion of diluted Lugol's iodine post-insemination in repeat breeder dairy cows improved the rate of service per conception and reduced the DO. Iodine deficiency couldn't be ignored because of the high temperature of the Sudan which might lead to reduction in thyroxin level and perturbing of the herd fertility [28]. The iodine could be absorbed from the genital tract, transferred to the thyroid gland and associated with thyroid binding globulin (TBG) in the thyroid gland to produce thyroxin [30]. Furthermore, Lugol's iodine has a broad spectrum bactericidal, fungicidal anti protozoa effect [31]. These activities of iodine will enhance the healing of the endometrium to restore its activities. Also, the internal cellular metabolism of the reproductive system including the ovaries will also be improved by infusion of diluted Lugol's iodine [28].

\section{Conclusion}

In conclusion, the repeat breeder syndrome among Sudan dairy cows is most likely due to subclinical endometritis, however, other causes could not be ignored particularly iodine deficiency. Furthermore, the syndrome can be treated successfully with intra-uterine infusion of $1 \%$ Lugol's iodine.

\section{References}

[1] H. M. Warriach, G Ahmad, and I. Ahmad. Effect of antibiotic treatment on pregnancy rate of repeat breeding dairy cross-bred cows with sub-clincal uterine infection. Pakistan Vet. J. 28 (1), 2008, $40-42$

[2] S. Katagiri. Anew approach to repeat breeding in cows. Treatments targeting the endometrial growth factor-cytokine network. J. of Vet. Med, Supp . (44); 2011, $51-53$.

[3] M. R. Ahmadi and S. A. Dehghan. Evaluation of the treatment of repeat breeder dairy cows with uterine lavage plus PGF2, with and without cephapirin. Turk. J. of Anim. Sci.31 (2), 2007, 125 - 129.

[4] P. C. Bartlett, J. Kirk and E. Mather. Repeated insemination in Michigan Holstein Friesian cattle: incidence descriptive epidemiology and estimated economic impact. Theriogenology (26), 1986, 309-322.

[5] M. Kimura, T. Nakao and K. Kawala. Luteal phase deficiency as a possible cause of repeat breeding in dairy cows. British Vet. J. (143), 1987, 560 - 566.

[6] A. V. N. Rao. Causes and incidence of reproduction disorders among Zebra x Taurus cross-bred cows. Theriogenology (17), 1982, $189-191$.

[7] F. O. Ahmed and A. S. Elshiekh. Uterine bacterial infection during postpartum delays recrudescence of reproductive traits in crossbred dairy cows. J Am Sci 9(6): 593-598.

[8] G. Frances, M. Davidson and E. Mayer. The influence of some nutritional factors on the incidence of the repeat breeder syndrome in high producing herds. Theriogenology (7), 1977, $105-111$.

[9] A. R. Peters. Embryonic mortality in the cow. Anim. Breed abstr. (64), 1996, 587 - 598.

[10] F. O. Ahmed, F. O. The efficacy of intra-uterine infusion of Iodine compounds on the reproductive efficiency of postpartum and repeat breeder dairy cows in the Sudan. PhD thesis, University of Khartoum, Sudan,2009.

[11] A. Dekriuf (1978): Factors influencing the fertility of a cattle population. J. Reprod. Fert. (57), 1978, 507- 518

[12] H. Gustafsson, K. Larsson, and A. Madej, A. (1986). Sequential endocrine changes and behavior during oestrus and metoestrus in repeat breeder heifers. Anim. Reprod. Sc. (10), 1986, $261-273$.

[13] P. Bage, H. Gustafsson, H. Forsberg, and B. Larsson (1997). Progesterone levels in repeat breeder heifers during pro and oestrous period. Theriogenology, (47), 1997, $141-142$.

[14] F. O. Ahmed and A. S. Elshiekh. Intrauterine infusion of Lugol's iodine improves the reproductive traits of postpartum infected dairy cows. IOSR-JAVS, 5(2), 2013, 89-94.

[15] S. Selvarajo, S. K. Agarwa and U. Shanker, U. Fertility responses and hormonal profile in repeat breeding cows treated with insulin. Anim. Reprod.Sci. (73), 2002, 141 - 149 .

[16] G. M. Wildman, J. Kotwiga, W. Slanger, and K. Johnson. Effects of suckling on pituitary responsiveness to GnRH hormones throughout the early postpartum of beef cows. J. Anim. Sci. (54), 1982, 594 - 603.

[17] G. I. Barrow and R. K. Feltham. Manual for the identification of medical Bacteria. ${ }^{\text {rd }}$. Cambridge university press, $1993,50-150$

[18] D. E. Noakes, L. Wallace and G. R. Smith. Bacterial flora of the uterus of cows after calving on two hygienically contrasting farm. Vet. Rec. (128), 1999, $440-442$

[19] F. O. Ahmed and A.S. Elsheikh. Reproductive performance of cross-bred dairy cows treated with $\mathrm{PGF}_{2} \alpha$ during early postpartum. J. Anim and Vet. Adv. 3(5), 2005, 329 - 334.

[20] G. H. Arthur, D. E. Noaks, P. Harold and T. J. Parkinson, T. J. (2001). Veterinary Reproduction and Obstetrics $8^{\text {th }}$ ed. W.B. Saunders Company Limited, 2001, $402-464$.

[21] A. S. Elsheikh and F. O. Ahmed. Backing up postpartum dairy cows with PGF $_{2} \alpha$. J. Anim. And vet Adv. 4(5), 2005,506 - 509.

[22] R. L. Geiser, H. Siegenthaler, and J. Martig. Effectiveness of local treatment using a PVP. Iodine compound for retained placenta in cows. Ber/munch Tierarztl Wochenschr. 108(7), 1995, 264 - 268.

[23] S. M. Elsanosi, and A. B. Eltyeb. sBacteria isolated from uterine washings from mares in the Sudan. Equine Vet. J. 11(4), 1979, 219 -222 .

[24] M. S. Edwell, K. Zduncz and T. Janowski, (2004). Comparative study on the efficacy of hormonal and non-hormonal treatment method in ovarian function affected dairy cows. Bull Vet. Instpulaway (48), 2004, 265 - 267. 
[25] G. N. Opsomer, Y. T., Grohn and A. Kruif, A. (2000). Risk factors for postpartum ovarian dysfunction in high producing dairy cows in Belgium. Theriogenology (53), 2000, $841-857$.

[26] G. F. Huszenicza, S, Janosi and A. R. Peters. Effects of clinical mastitis on ovarian function in postpartum dairy cows. Reprod. In Domest. Anim. 40 (3),2005, $199-204$.

[27] Y. B. Grohan, H. Erb and H. Saoloemi. Epidemiology of reproductive disorders in dairy cattle. J. Prev. Med. (8), 1995,25 -39.

[28] A. K. Sarkar. Therapeutic management of anoestrus cows with diluted Lugol's iodine and massage on reproductive organs. J. of Anim. Vet. Sci. 1(1), 2006, 30 - 32.

[29] A. D. Koujan, E. M. Hussein, M. Ayoub and M. Afiefy, M. (1996). Therapeutic efficacy of Povidone iodine (Bectadine and Dichloroxylenol) (Septocid) in Holstein cows affected with endometritis and/or cervicitis. Acta. Vet. Hung. 44 (1), 1996,111 - 119.

[30] O. H. Yu and M. H. Tak-yin. The efficiency of Povidone iodine pessaries in a start, low-dose treatment regime on candidal, trichomonal and nonspecific vaginitis. Posgrad. Med. J. 69(sppl3), 1993, $58-61$.

[31] I. M. Sheldon, G. S. Lewis, S. Le Blanc, and R. O. Gilbert. Defining postpartum uterine disease in cattle. Theriogenology 65 (8), 2006, 1516 - 1530 